\title{
Improved Microstrip Antennas with Novel EBG Structure for WLAN Applications

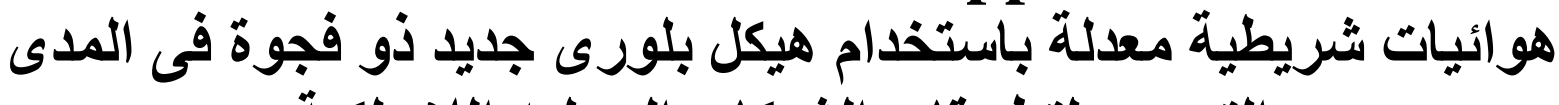

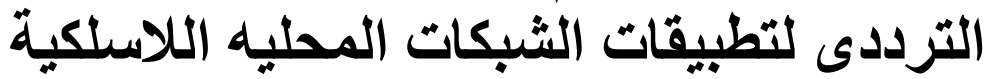

\author{
Rehab M. H. Abo El Atta ${ }^{1}$ and Nihal F. F. Areed ${ }^{2}$ \\ mathteachear_2006@yahoo.com¹,nahoolaf@yahoo.com \\ ${ }^{1,2}$ Department of Electronics and Communications Engineering, Faculty of \\ Engineering,
}

يستعرض هذا البحث تصميم وتحليل نموذج بسيط مكتنز لهياكل البلورات ذات الفجوة فى النطاق الترددى (EBG) باستخدام طريقة الفروق المحدودة فى النطاق الزمنى. يتكون الهيكل المقترح من رقائق معدنية مربعة رتبت على شئ شكل حلقات

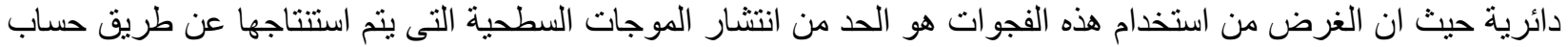

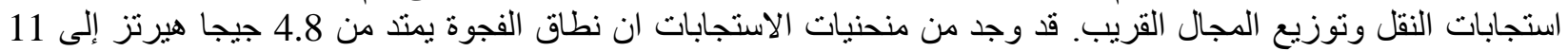

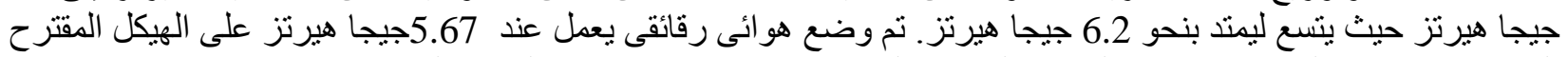

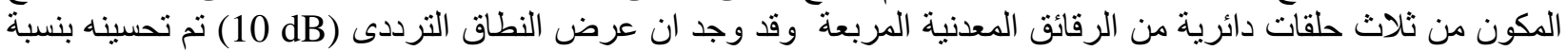

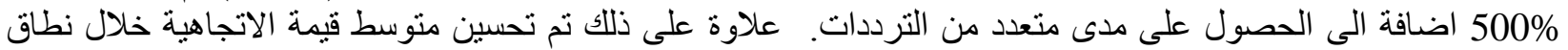

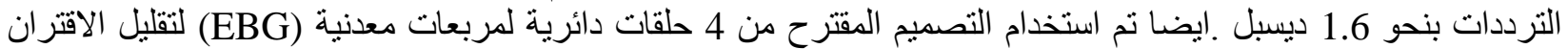

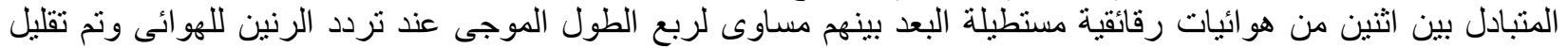

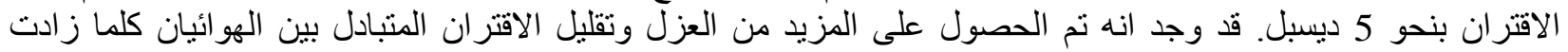

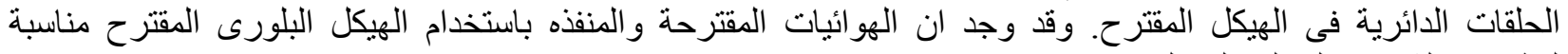
لتطبيقات الثبكات المحليه اللاسلكيه.

\section{Abstract}

In this paper, a novel simple compact electromagnetic band gap (EBG) configuration is proposed and analyzed using 3D finite difference time domain (FDTD) method. The proposed EBG structure consists of metallic square patches that arranged on ordered circular rings. The bandgap feature of surface wave suppression is demonstrated by calculating the transmission responses and near field distributions. From the investigated transmission curves, the surface wave bandgap is found to be $6.2 \mathrm{GHz}$ and extends from $4.8 \mathrm{GHz}$ to $11 \mathrm{GHz}$. By inserting a $5.67 \mathrm{GHz}$ patch antenna over the proposed 3-rings EBG structure, the $-10 \mathrm{~dB}$ bandwidth has been enhanced by around $500 \%$ and the multiband ability is investigated. Further, the average value of the directivity over the wide frequency band has been improved by around $1.6 \mathrm{~dB}$. On top of that, the design of 4-rings EBG structure is used to decrease the mutual coupling between two coupled rectangular patches with planar separation of quarter the wavelength by $5 \mathrm{~dB}$. Much isolation between closely-packed antenna elements can be easily achieved by using more EBG circular rings. The proposed Microstrip antennas that utilize the proposed EBG structure are appropriate for WLAN applications

\section{Index terms}

Microstrip patch antenna, EBG structure, mutual coupling, 3D FDTD. 


\section{Introduction}

In recent years, compact, broadband, multiband antennas have attracted much attention among researchers due to their small size, low cost and high data rate features [1-2]. Electromagnetic band gap structures (EBG) such as dielectric rods, holes, mushroom like EBG have winning features of compactness and surface wave suppression. These features help to improve the matching and radiation characteristics of the patch antennas [3-4].

The scope of this paper is to propose and simulate novel, simple and compact EBG configuration based on mushroom like EBG [1]. The proposed EBG structure for surface wave suppression is composed of metallic square patches that arranged on ordered circular rings. 3D FDTD [5] method is applied to calculate the transmission responses and investigate the stopband of the proposed EBG configuration. Based on the estimated numerical results, the surface wave bandgap width is found to be $6.2 \mathrm{GHz}$ and extends f1rom $4.8 \mathrm{GHz}$ up to $11 \mathrm{GHz}$. By integrating a $5.67 \mathrm{GHz}$ patch antenna and the proposed EBG structure with different configurations, the $10 \mathrm{~dB}$ bandwidth has been improved by around $500 \%$. Moreover multiband zones at $6 \mathrm{GHz}, 7 \mathrm{GHz}$ and 9.8 $\mathrm{GHz}$ are obtained. Further, the average value of directivity over the wide frequency band has been improved by around $1.6 \mathrm{~dB}$. On top of that, a significant $5 \mathrm{~dB}$ mutual coupling reduction is verified between two coupled $5.67 \mathrm{GHz}$ patch antennas with planar separation of $0.25 \lambda_{\mathrm{o}}$ by using the proposed 4rings EBG structure.

The paper is organized as follows. The proposed EBG structure has been added in section II. Next, the applications of the EBG into microstrip patch antennas have been introduced in section III. Finally conclusion is drawn

\section{EBG Structure and Band-Gap Characterization}

Initially, the utilized FDTD numerical technique has been validated by analyzing the EBG structure shown in Fig.1 (a) [6]. In [6], the EBG structure consists of square array of metallic identical square patches each has a short bin with diameter of 0.5 $\mathrm{mm}$. The gap between the patches is 0.25 $\mathrm{mm}$ while the period of the cell is $3.5 \mathrm{~mm}$.

In order to investigate and quantify the bandgap features of the EBG structures, the method of suspended microstrip line which is proposed by Fan [7] is applied. In this method, a construction of microstrip line placed on a dielectric support layer of thickness $1 \mathrm{~mm}$ is inserted on the EBG structure as shown in Fig. 2.

Figure 3 (a) shows the calculated magnitude of $S_{21}$ as a function of frequency for the EBG structure shown in Fig.1 (a). It is evident from the figure that, a distinct EBG extending from $7.5 \mathrm{GHz}$ up to $8.7 \mathrm{GHz}$ is created. The obtained results have an excellent agreement with the results published by [6].

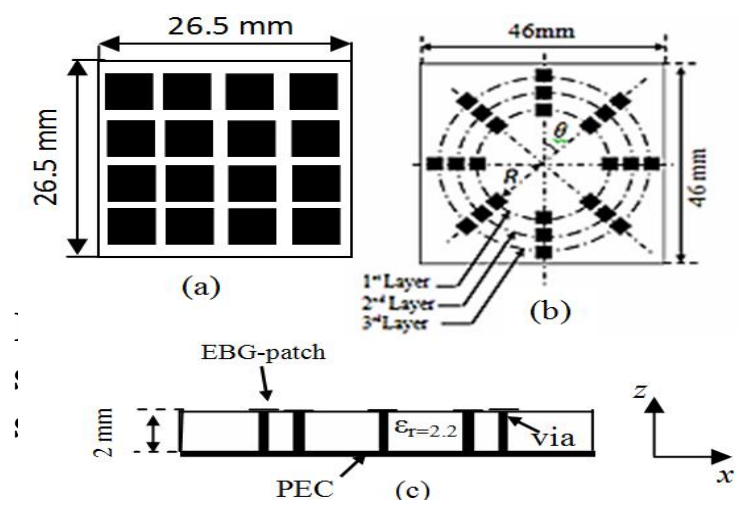

simulation models for the proposed EBG structure. The figure shows that the proposed configuration comprises four main parts: a ground plane, a dielectric substrate, metallic square patches, and connecting vias. In FDTD simulation, EBG patches are constructed on a $2 \mathrm{~mm}$ thick substrate with relative permittivity of 2.2. Further, the width of the EBG square patch, the gap 
between the circular arrangement layers, the spacing angle and the radius of first layer are called $d$, a, $\theta$ and $R$, respectively.

Here, FDTD method is used to investigate the appropriate mesh cell size in order to simulate the proposed structure accurately. In these simulations, the initial geometrical parameters of the proposed 3-layers EBG structure are chosen to be $\mathrm{d}=3.2 \mathrm{~mm}, R=$ $11 \mathrm{~mm}, \theta=45^{\circ}$, and $\mathrm{a}=1 \mathrm{~mm}$. Figure (3) shows the variation of $S_{21}$ parameter with different mesh densities. It can be noted from this figure that, to keep a reasonable accuracy, this structure should be discretized with a mesh cell size equals to $\lambda / 40$ or less.

Next, FDTD numerical method has been applied to investigate the effect of the structure geometrical parameters on the surface bandgap of the EBG configuration [5]. First, the effect of the square patch size $d$ on the transmission magnitude is studied while the other parameters are kept constant at their initial values. Figure 4(a) shows the calculated $S_{21}$ magnitude for different values of the patch size $d$. It can be noted from this figure that, the width of the stop band $\left(\mathrm{S}_{21}\right.$ below -20 dB) [8-11] increases as the size of the patch increases. Next, the effect of the spacing angle $\theta$ is studied while the other parameters are kept constant at their initial values. Figure 4(b) shows the calculated magnitude of $S_{21}$ as a function of $\theta$. It is evident from the figure that, a distinct EBG extending from $4.8 \mathrm{GHz}$ to $11 \mathrm{GHz}$ is created using aligned EBG patches with $\theta$ equals to $30^{\circ}$ or $45^{\circ}$. The effect of increasing the EBG layers on the surface wave bandgap of the EBG configuration is also investigated.

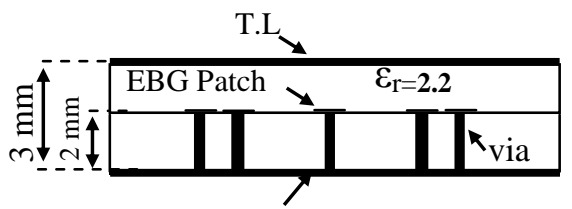

PEC

Fig.2. Side view of the modeling using suspended
microstrip transmission line method
Fig.2. Side view of the modeling using suspended
microstrip transmission line method

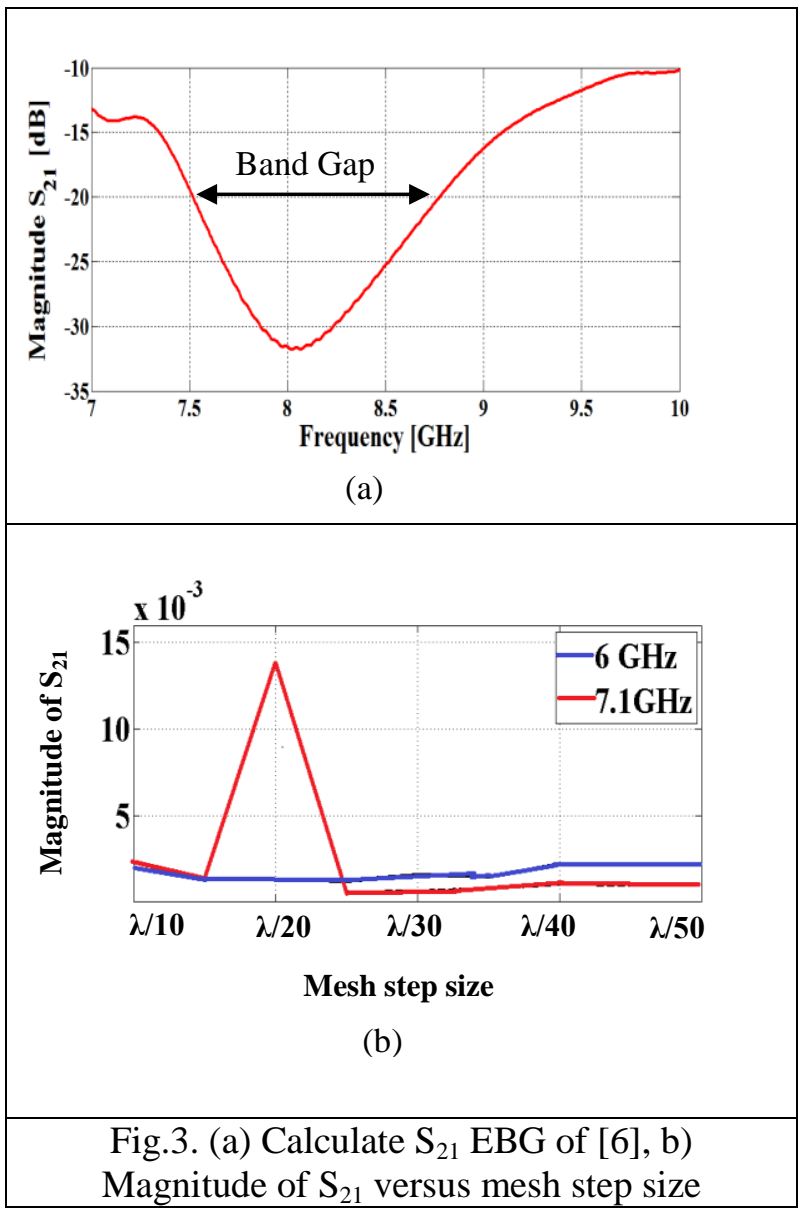

Figure 4(c) shows the calculated magnitude of $S_{21}$ for different EBG layers. It can be found form the figure that, the $E B G$ is created and its bandwidth increases with the increase of the number of EBG layers.

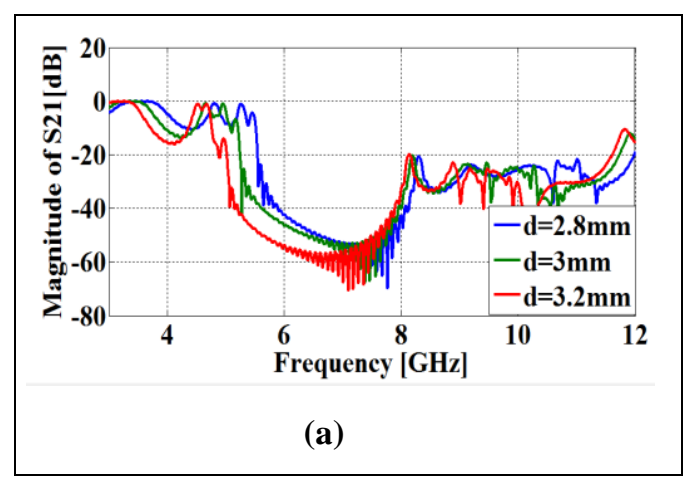




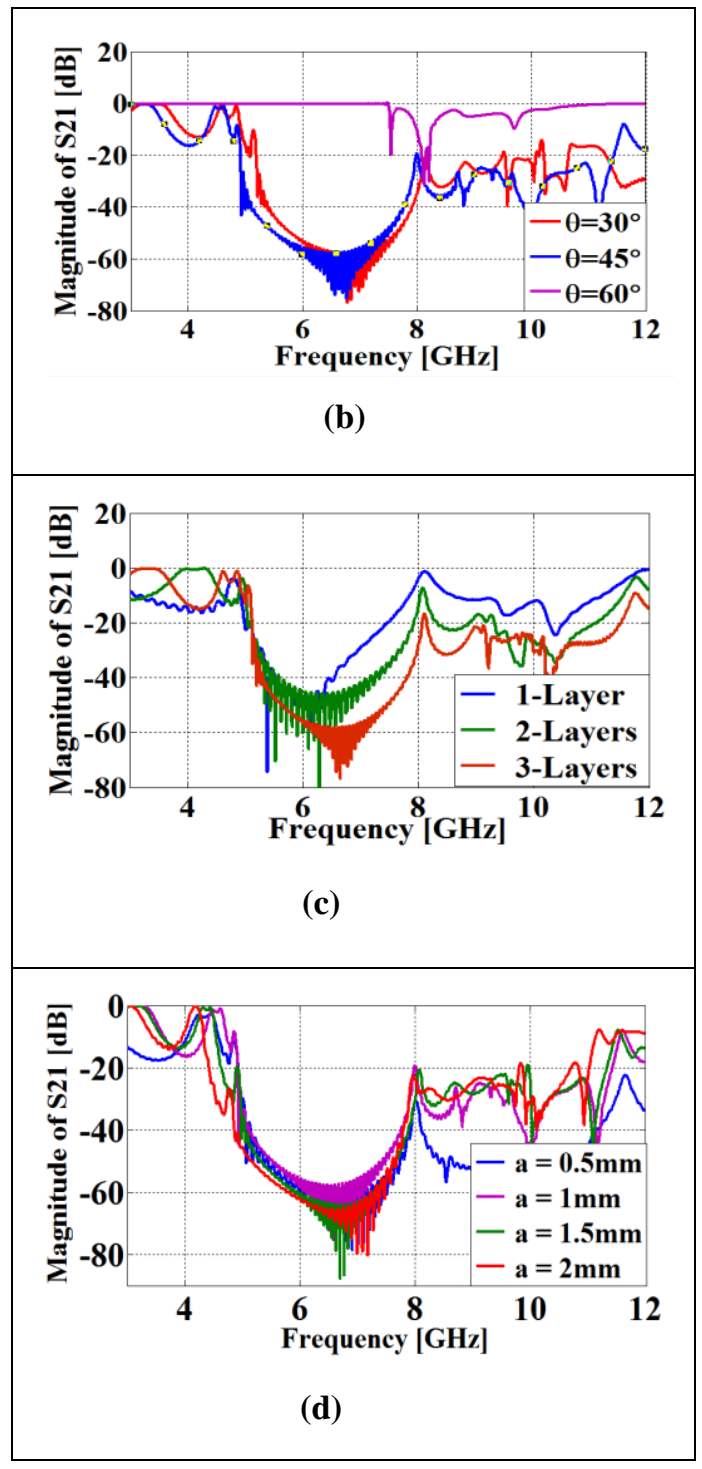

Fig.4. (a) The transmission coefficient S21 for different patch sizes $2.8 \mathrm{~mm}, 3 \mathrm{~mm}$, $3.2 \mathrm{~mm}$, (b) S21 for 3-layers EBG structure with different rotations angle $\theta$, (c) The transmission coefficient S21 for EBG structure with $\theta$ of $45^{\circ}$ for different number of layers, (d) The transmission coefficient S21 of EBG structure with different gap distance between the circular alignment layers.

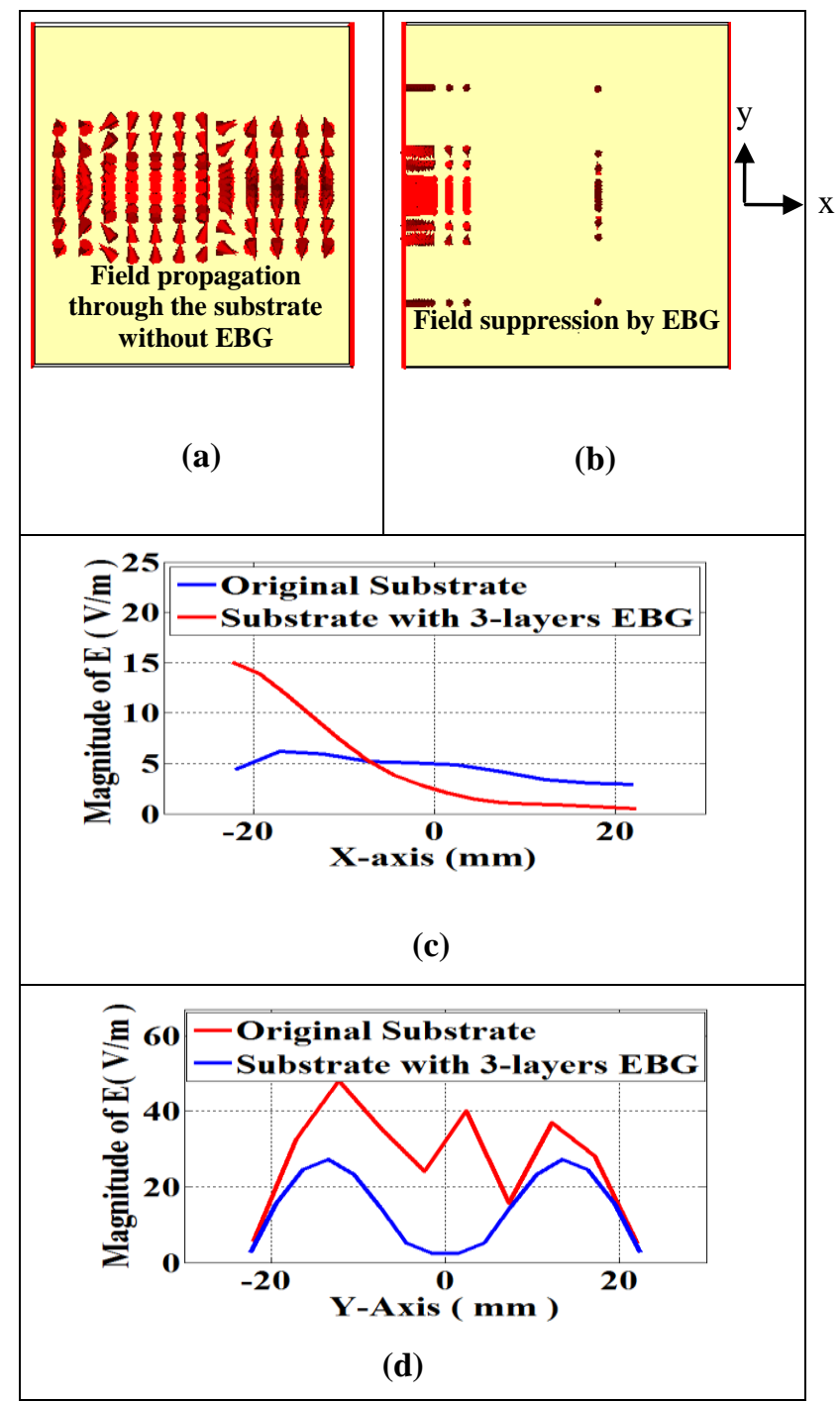

Fig.5. (a) and (b) are snap shots for the 2-D E-field distribution in the substrate without and with EBG respectively, (c) and (d) are snap shots for the 1-D E-field distribution in the substrate without and with EBG: (c) E field along $\mathrm{x}$-axis, (d) E field along $\mathrm{y}$-axis.

Finally, the effect of the planar separation distance between the circular alignment layers on the transmission magnitude $S_{21}$ is also studied shown in Fig.4 (d). It is evident from this figure that decreasing the spacing between the circular layers a to $0.5 \mathrm{~mm}$ approximately doubled the bandwidth of the suppressed waves compared with that of the suppressed waves at spacing $\mathrm{a}=2 \mathrm{~mm}$. Figures 4 (e) and 4 (f) show the E-field 
distribution along the horizontal plane xy of the substrate without and with 3-layers EBG structure at $6 \mathrm{GHz}$. It is evident from the figures that, regardless the zone of input, the field is distributed along the substrate without EBG but its values vanished along the substrate with EBG.

Figures 5(c) and 5 (d) show the one dimension E-field distribution along the $x$ axis and $y$-axis of the horizontal plane of the substrate without and with 3-layers EBG structure. It is evident from these figures that, adding EBG patches inside the substrate results in preventing the fields to propagate along the substrate at $6 \mathrm{GHz}$. These field distributions clearly agree with the behavior of $S_{21}$ shown earlier in Fig.4.

\section{Applications to Patch Antennas}

In the following subsections, the proposed EBG structure is applied to improve the matching and radiation characteristics of a $5.67 \mathrm{GHz}$ rectangular patch antenna. The FDTD simulation results reveal that, the $(10-\mathrm{dB})$ bandwidth has been enhanced by around $500 \%$ and the average value of the directivity over the obtained wide frequency band has been improved by around $1.6 \mathrm{~dB}$. Further, the proposed EBG structure is used to isolate two-coupled rectangular patch antennas through reducing the mutual coupling between them by about $5 \mathrm{~dB}$ at the operating frequency $5.67 \mathrm{GHz}$.

\subsection{One-Element Rectangular Patch Antenna}

This section shows the use of the EBG substrate to improve the radiation characteristics of a $5.67 \mathrm{GHz}$ one element rectangular patch antenna. The simulations have been performed using 3D FDTD method.

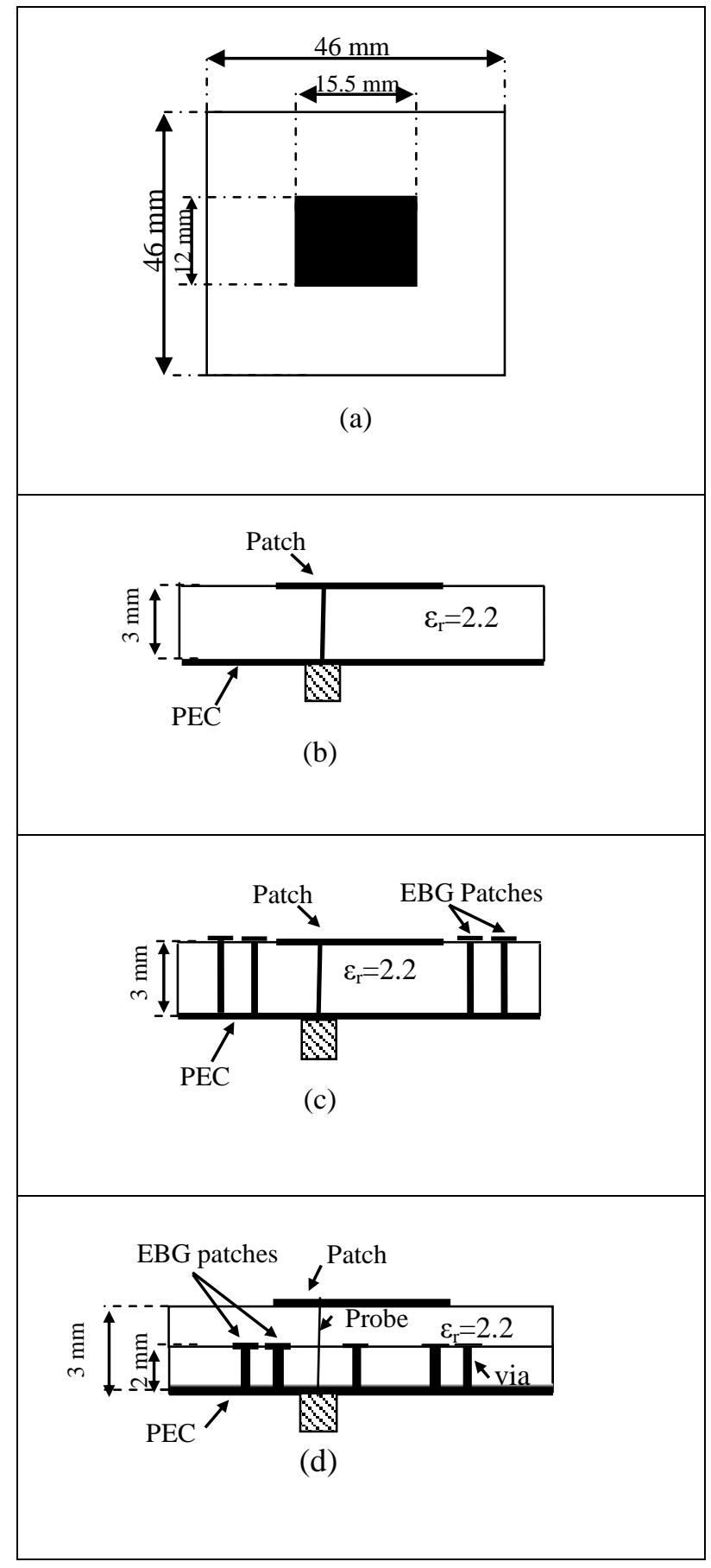

Fig.6: (a), (b) Top and side views of the conventional rectangular patch antenna, (c) and (d) Side views of the rectangular patch antenna and the proposed EBG structure with different alignments. 
Figures 6(a) and 6(b) show the top and side views of a rectangular patch antenna using original substrate. The rectangle patch is fed by coaxial probe has dimensions of 15.5 $\mathrm{mm} \times 12 \mathrm{~mm}$, the substrate has permittivity of 2.2 and thickness of $3 \mathrm{~mm}$ and the underneath ground plane has dimensions 46 $\mathrm{mm} \times 46 \mathrm{~mm}$. Figure 6(c) shows the side view for the considered rectangular patch antenna with EBG patches in the same plane over a thick $3 \mathrm{~mm}$ substrate. Figure 6(d) shows the side view for the considered rectangular patch antenna with a substrate having sandwiched 3-layers of EBG patches. By applying the FDTD method the simulation results are shown in figure (7). Figure 7(a) shows the calculated $S_{11}$ of the rectangular patch shown in Figs. 6(b) and 6(c). The figure shows that using EBG with $\theta$ of $30^{\circ}$ or $45^{\circ}$ results in antenna with multiband resonances at $6 \mathrm{GHZ}, 7 \mathrm{GHZ}$ and 9.8 GHZ compared with single resonance at $5.67 \mathrm{GHz}$ by antenna without EBG.

Further, a rectangular patch designed on a substrate having inside 3-layers of EBG patches with $\theta$ of $45^{\circ}$ is numerically analyzed. Figure 7(b) shows the calculated $S_{11}$ of the rectangular patch shown in Fig. 6(b) and 6(d). The figure shows that the 10$\mathrm{dB}$ bandwidth of the rectangular patch with EBG is extended from $5.74 \mathrm{GHz}-7.53 \mathrm{GHz}$ which is greater than that of antenna without EBG by about $1.4 \mathrm{GHz}$. Another important parameter which is highly considered and calculated is the directivity of the antenna [10]. It should be noted from Fig.7(c) that, the average value of the directivity for the rectangular patch with EBG is enhanced along the gained wide frequency band to 8.1 $\mathrm{dB}$ compared to $6.5 \mathrm{~dB}$ of the rectangular patch without EBG. Figure 7(d) shows the calculated efficiency for the rectangular patch antenna with and without EBG layers. The figure shows that the average efficiency for the rectangular patch with EBG is imroved over the entire frequency band to about 0.9 compared to 0.25 of the rectangular patch without EBG.

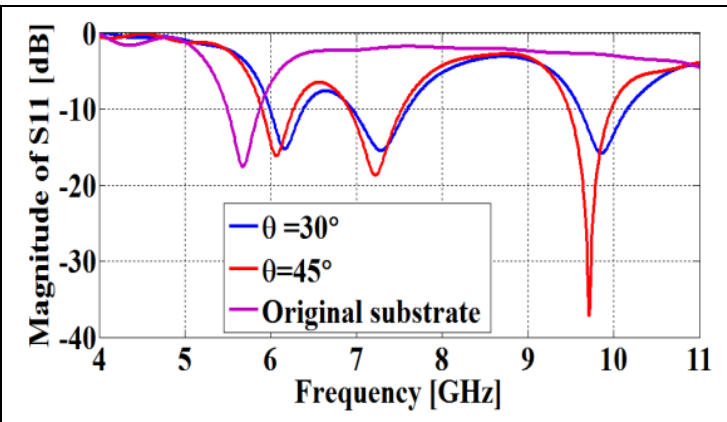

(a)

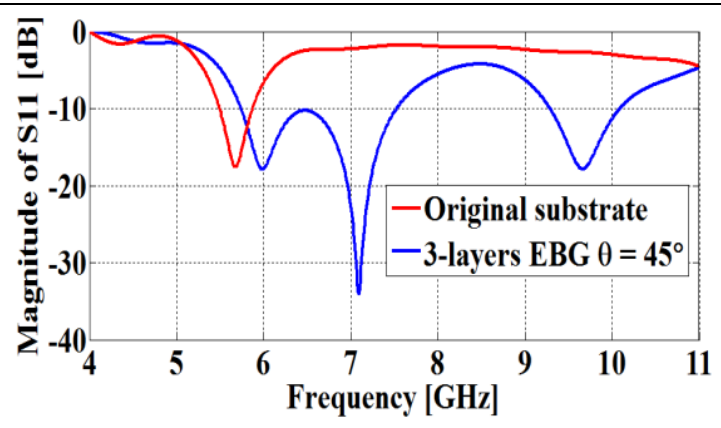

(b)

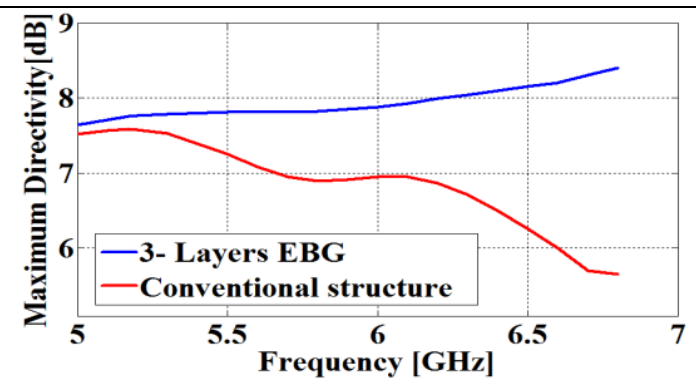

(c)

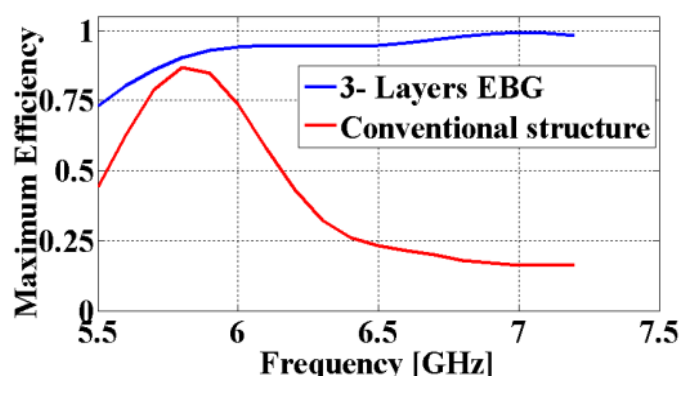

(d)

Fig . 7.(a) $S_{11}$ for the rectangular patch with normal substarte and substrate with EBG structures (b) $\mathrm{S}_{11}$ for the rectangular patch 
with normal substarte and substrate with EBG structures, (c) The directivity vs. frequency, (d) The efficiency vs. frequency.

\subsection{Two Coupled Rectangular Patch Antennas}

Surface waves play a dominant role in increasing the mutual coupling between two microstrip antennas that are placed from one another by quarter the wavelength and hence degrading their performance [12-14]. It has been proved that the E-plane coupled microstrip antennas exhibit much stronger mutual coupling than the H-plane coupled ones [9-11]. To reduce the mutual coupling and overcome performance degradation, the proposed EBG structure has been used. Figures 8(a) and 8(b) show the top and side views of $E$-plane coupled antennas with planar separation of $0.25 \lambda_{\mathrm{o}}$. It should be noticed from the figure that, the proposed EBG has been inserted inside the substrate with permittivity of 2.2 and thickness of 3 $\mathrm{mm}$. The calculated mutual coupling $\mathrm{S}_{21}$ curves between the two rectangular patches with and without the proposed EBG patches are shown in Fig. 8(c). It can be noticed from that figure that, the mutual coupling $\mathrm{S}_{21}$ at $5.67 \mathrm{GHz}$ equals to $-15 \mathrm{~dB}$ between patches with homogenous dielectric substrate and decreases to $-17 \mathrm{~dB},-18.4 \mathrm{~dB}$ and $-20 \mathrm{~dB}$ after adding 2-layers EBG, 3-layers and 4layers EBG inside the dielectric substrate, respectively. Much isolation between the two closely-packed antenna elements can be easily achieved by using more EBG circular layers. These results show that the proposed EBG structure represents a significant tool for isolating antenna elements with planar separation of $0.25 \lambda_{0}$.

\section{Conclusion}

It has been shown that a new simple compact electromagnetic band gap (EBG) configuration is presented in this paper. The suggested EBG consists of metallic square patches that arranged on ordered circular rings and is numerically simulated using 3DFDTD method. The transmission responses and the near field distributions have been used to investigate the bandgap features of the proposed EBG structure. From the calculated transmission curves, the width of the surface wave bandgap is found to be 6.2 $\mathrm{GHz}$ and extends from $4.8 \mathrm{GHz}$ to $11 \mathrm{GHz}$. The proposed EBG structure is applied to improve the matching and radiation characteristics of a $5.67 \mathrm{GHz}$ rectangular patch antenna.

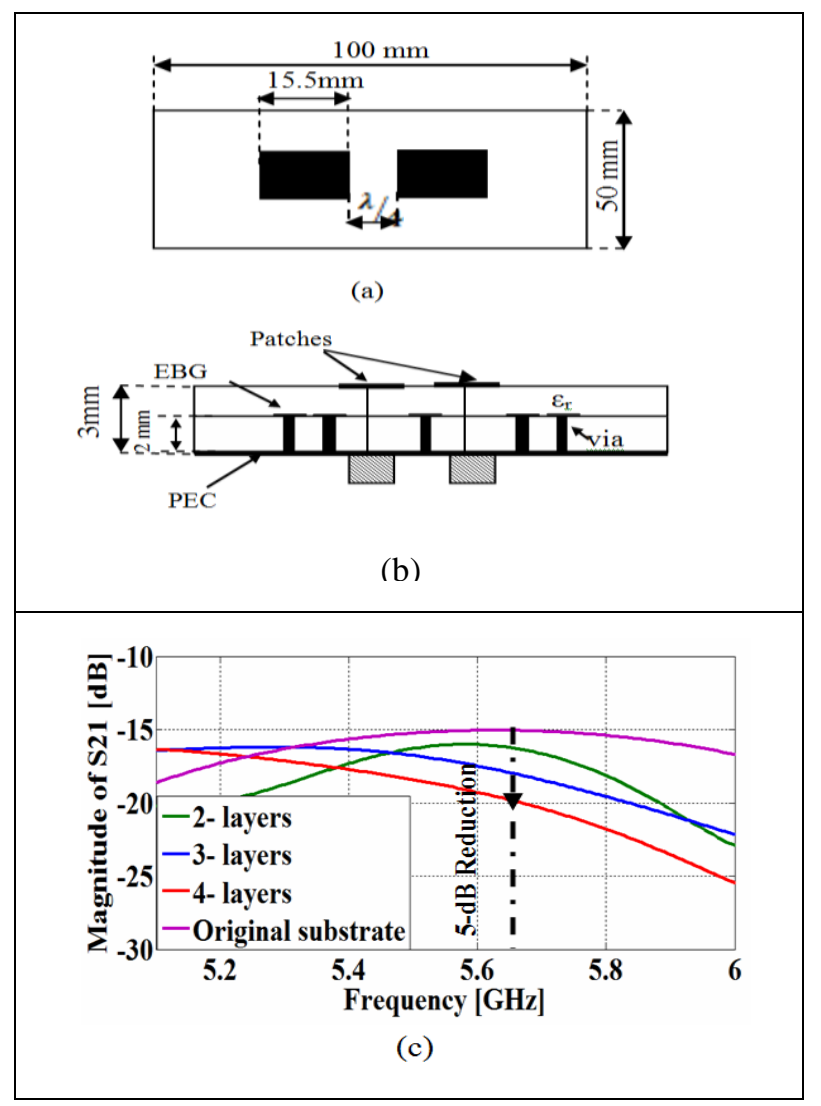

Fig .8: Two coplanar patches: (a) Top view, (b) side view, (c) Mutual coupling between two patches without EBG with different number of layers

The FDTD simulation results reveal that, the 10-dB bandwidth has been enhanced by around $500 \%$ and the average value of the directivity over the gained wide frequency band has been improved by around $1.6 \mathrm{~dB}$. 
Further, the proposed 4-layers EBG structure is effectively used to isolate two-coupled rectangular antennas through reducing the mutual coupling between them by about $5 \mathrm{~dB}$. Excessive isolation between the two closely-packed antenna elements can be easily achieved by using more EBG circular layers.

\section{Refrences}

[1] H. R. Cheng, Q. Y. Song, Y. C. Guo, X. Q. Chen and X. W. Shi, "Design of a novel EBG structure and its application in fractal microstrip antenna," J PIER C, vol. 11, pp. 81-90, 2009.

[2] A. Ahmed and Yogesh ,"Electromagnetic Band Gap Coupled Microstrip Antenna for UWB Applications," (IOSRJECE), vol. 2, no. 6, pp. 01, Sep. 2012.

[3] A. K. Gupta, R. K. Prasad, and D. K. Srivastava, "Design and Analysis of Dual-Band C-Shaped microstrip patch antenna," J. of Advances in Engineering \& Technology, vol. 4, no.2, pp. 311-317, Sept 2012.

[4] D. N. Elsheakh, H. A. Elsadek, E. A. Abdallah, M. F. Iskander, and $\mathrm{H}$. Elhenawy, "Investigated new embedded shapes of electromagnetic bandgap structures and via effect for improved microstrip patch antenna performance," J. of PIER B, vol. 20, pp. 91-107, 2010.

[5] Taflov and S. C. Hagness, Computational Electrodynamics: The Finite Difference Time Domain Method. $3^{\text {rd }}$ Ed., London: Artech House, Boston, 2005.

[6] M. Rahman and M. Stuchly,"Wide-band microstrip patch antenna with planar PBG structure," Proc. IEEE APS Dig., vol. 2, pp. 486-490, 2001.

[7] L. Yang, M. Fan, F. Chen, J. She, and Z. Feng, "A Novel Compact Electromagnetic-Bandgap (EBG) Structure and Its Applications for
Microwave Circuits," IEEE Trans, microwave theory and techniques, vol. 53, no.1, pp. 183-190, Jan. 2005.

[8] J.M. Y. Fan, R. H, Z. H. Feng, X.X. Zhang and Q. Hao, "Advance in 2-DEBG research," Infrared Millimeter Waves, vol.22,no.2, 2003.

[9] F. Yang and Y. Rahmat-Samii, "Applications of Electromagnetic Band-Gap (EBG) Structures in Microwave Antenna Designs," Proc. of 3rd International Conference on Microwave and Millimeter Wave Technology, pp. 28-31, 2002.

[10] N. Kushwaha and R. Kumar, "An UWB Fractal Antenna with Defected Ground Structure and Swastika Shape Electromagnetic Band Gap," J PIER B, vol. 52, pp. 383-403, 2013.

[11] M. S. Alam, N. Misran, B. Yatim,and M. T. Islam, "Development of Electromagnetic Band Gap Structures in the Perspective of Microstrip Antenna Design," J. of Antennas and Propagation, 2013.

[12] C. K. Ghosh, B. Mandal, and S. K. Parui, "Mutual Coupling Reduction of a Dual-Frequency MicrostripAntenna Array by Using U-Shaped DGS and InvertedU-Shaped Microstrip Resonator," J. PIER C, vol. 48, pp. 6168, 2014.

[13] F. Yang and Y. Rahmat-Samii, "Microstrip Antennas Integrated With Electromagnitic Band-Gap (EBG) Structures:A low Mutual Coupling Design for Array Applications," IEEE Trans, vol. 51, no. 10, pp. 2936- 2946, October 2003.

[14] A. B. Abdel-Rahman, "coupling reduction of antenna array elements using small inter-digital capacitor loaded slots," J PIER C, vol. 27, pp. 15-26, 2012. 